http://jmscr.igmpublication.org/home/ ISSN (e)-2347-176x ISSN (p) 2455-0450 crossref DOI: https://dx.doi.org/10.18535/jmscr/v8i3.75

\title{
Admission Blood Pressure As a Prognostic Marker in Acute Ischemic Stroke
}

\author{
Authors \\ Dr Vishwanath Reddy. $\mathbf{N}^{1}$, Dr Manchu. Deepthi ${ }^{2}$ * \\ ${ }^{1,2}$ Department of Medicine, Sri Devraj Urs Medical College, Kolar, Karnataka, India \\ *Corresponding Author \\ Dr Manchu Deepthi \\ Department of Medicine, Sri Devaraj URS Medical College, Kolar, Karnataka, India
}

\begin{abstract}
Objective: To evaluate the relationship between Blood pressure (systolic blood pressure (SBP), diastolic blood pressure (DBP) and mean arterial pressure) on admission and early mortality and morbidity in acute stroke patients and to see the prognostic significance of BP with mortality and morbidity in inpatients

Design: Hospital based prospective observational study

Setting: Conducted in the Department of General Medicine at Sri Devaraj Urs medical college, Kolar, Karnataka.

Subjects: A total of 100 patients admitted within 24 h from stroke. Main outcome measures are Mortality at 1 and 3 day after stroke in relation to admission SBP and DBP.

Results: $77.8 \%$ Mortality was seen in the subjects who had admission SBP of 161-180mmhg. $75 \%$ Mortality was seen in the subjects who had admission SBP>180mmh. Both the extremity low and high admission SBP had very high mortality. $60 \%$ Mortality was seen in the subjects who had admission DBP 60-69mmhg. 85.7\% Mortality was seen in the subjects who had DBP $\geq 110$ mmhg. Both the extremity low and high admission DBP had very high mortality.

Conclusion: The described U-shaped curve appears to relate BP to clinical outcome, with the best outcome observed in normal or mildly elevated admission BP values, suggesting that both extremely high and extremely low admission BP-values are likely to affect outcome adversely.

Keywords: acute stroke, blood pressure, ischaemic stroke, mortality.
\end{abstract}

\section{Introduction}

Stroke is the third leading cause of death in Western populations after coronary heart disease and cancer. Furthermore, stroke is the most common life-threatening neurological disorder, and the resulting disability is the most important single cause of inability among these populations. ${ }^{1}$ Blood pressure (BP) is initially elevated in patients with acute stroke and usually declines spontaneously within the first few days after admission. ${ }^{2-3}$ It is still unknown whether reactive post stroke hypertension represents a pathophysiological response to ischemia to maintain collateral blood flow to the ischemic penumbra or whether it is a sign of the severity of stroke. $^{4-7}$

Data on the prognostic significance of BP levels following acute stroke are conflicting.

Observational studies have suggested that high initial BP is associated with increased stroke 
mortality, ${ }^{8-11}$ impairment of functional outcome ${ }^{11}$,

12 and stroke recurrence ${ }^{11,13}$ whilst others failed to support these findings. ${ }^{14-15}$

Some studies also indicated that low admission BP correlates with poor prognosis. ${ }^{11,13}$

Methodological differences in the design of studies assessing the prognostic significance of BP after acute stroke may explain some of the conflicting evidence.

The aim of the present study was to evaluate the relationship between Blood pressure (systolic blood pressure (SBP), diastolic blood pressure (DBP) and mean arterial pressure) on admission and early mortality and morbidity in acute stroke patients and to see the prognostic significance of BP with mortality and morbidity in inpatients. We will examine the BP- stroke mortality curves, as well as the relationship between BP- values and cause of death.

In this study we had also study the morbidity of the patients with national institutes of health stroke scale (NIHSS) on admission and after 1 week and see its correlation with admission BP.

\section{Materials \& Methods}

Study Setting: A study was conducted in the Department of General Medicine at Sri Devaraj Urs medical college, Kolar, Karnataka.

Study Design: Hospital based prospective observational study

Sample Size: 100

\section{Method of Collecting Data}

Patients who presented in the emergency room of our hospital in <24hrs after symptom onset and were hospitalized. Casual supine BP was measured at hospital admission, thrice using a standard mercury sphygmomanometer and a mean is a taken to exclude human error. Glasgow Coma Scale was used for the estimation of the neurological status on admission. On admission all patients were examined, and impairment quantified with NIHSS scale and they had undergo an initial computed tomography (CT) scan of the brain or MRI brain plain and followed for one-week duration of stay at our hospital and at the end of one-week NIHSS scale is again assessed and the data collected was analysed to prove the prognostic significance of $\mathrm{BP}$ in acute ischemic stroke.

\section{Inclusion Criteria}

- Patients with clinical suspicion of stroke

\section{Exclusion Criteria}

- Transient ischemic stroke

- Haemorrhagic stroke

- Age $<18$ years

\section{Statistical Analysis}

Data was entered into Microsoft excel data sheet and was analyzed using SPSS 22 version software. Categorical data was represented in the form of Frequencies and proportions. Chi-square test or Fischer's exact test (for $2 \times 2$ tables only) was used as test of significance for qualitative data. Continuous data was represented as mean and standard deviation. Independent $t$ test was used as test of significance to identify the mean difference between two quantitative variables. ANOVA was used as test of significance to identify the mean difference between more than two quantitative variables. Correlations were performed with Pearson Correlation coefficient. $\mathrm{P}$ value (Probability that the result is true) of $<0.05$ was considered as statistically significant after assuming all the rules of statistical tests.

Statistical Software: MS Excel, SPSS version 22 (IBM SPSS Statistics, Somers NY, USA) was used to analyze data

\section{Results}

During the study period we have included 100 subjects. Out 100 subjects 34 were female and 66 were male. The ratio of Female:Male was 1: 3.The mean age of the study subjects was $65.31 \pm$ $10.61 \mathrm{yrs}$ with minimum age was $45 \mathrm{yrs}$ and maximum was 92yrs.39 subjects had Hypertension and only 9 subjects had type 2 diabetes mellitus. Smoking history was present in $44 \%$ of the subjects and Alcohol intake history was present in $33 \%$ of the subjects. 
The mean systolic BP was $142 \pm 22.97$ mmhg with minimum 90mmhg and maximum 240mmhg, mean diastolic BP was $86.62 \pm 14.62 \mathrm{mmhg}$ minimum 60mmhg and maximum 150mmhg, mean MAP was $105.34 \pm 16.88$ mmhg minimum $70 \mathrm{mmhg}$ and maximum 180mmhg. Out of 100 subjects 30 died and 70 survived at the end of the study.

Table 1: Association of Various parameter with the outcome

\begin{tabular}{|c|c|c|c|c|c|c|}
\hline & & \multicolumn{2}{|c|}{ Survived } & \multicolumn{2}{|c|}{ Dead } & \multirow[t]{2}{*}{ P Value } \\
\hline & & $\begin{array}{c}\text { No of } \\
\text { subjects }\end{array}$ & Percentage & $\begin{array}{c}\text { No of } \\
\text { subjects }\end{array}$ & Percentage & \\
\hline \multirow[t]{5}{*}{ Age Group } & 45-54yrs & 12 & $80.0 \%$ & 3 & $20.0 \%$ & \multirow[t]{5}{*}{0.026} \\
\hline & 55-64yrs & 25 & $86.2 \%$ & 4 & $13.8 \%$ & \\
\hline & 65-74yrs & 25 & $65.8 \%$ & 13 & $34.2 \%$ & \\
\hline & 75-84yrs & 5 & $38.5 \%$ & 8 & $61.5 \%$ & \\
\hline & $85-94 y r s$ & 3 & $60.0 \%$ & 2 & $40.0 \%$ & \\
\hline \multirow[t]{2}{*}{ Gender } & Female & 22 & $64.7 \%$ & 12 & $35.3 \%$ & \multirow[t]{2}{*}{0.407} \\
\hline & Male & 48 & $72.7 \%$ & 18 & $27.3 \%$ & \\
\hline \multirow[t]{2}{*}{ Hypertension } & No & 48 & $78.7 \%$ & 13 & $21.3 \%$ & \multirow[t]{2}{*}{0.025} \\
\hline & Yes & 22 & $56.4 \%$ & 17 & $43.6 \%$ & \\
\hline \multirow[t]{2}{*}{ Diabetes Mellitus } & No & 65 & $71.4 \%$ & 26 & $28.6 \%$ & \multirow[t]{2}{*}{0.446} \\
\hline & Yes & 5 & $55.6 \%$ & 4 & $44.4 \%$ & \\
\hline \multirow[t]{2}{*}{ Smoking } & No & 38 & $67.9 \%$ & 18 & $32.1 \%$ & \multirow[t]{2}{*}{0.664} \\
\hline & Yes & 32 & $72.7 \%$ & 12 & $27.3 \%$ & \\
\hline \multirow[t]{2}{*}{ Alcohol } & No & 48 & $71.6 \%$ & 19 & $28.4 \%$ & \multirow[t]{2}{*}{0.647} \\
\hline & Yes & 22 & $66.7 \%$ & 11 & $33.3 \%$ & \\
\hline
\end{tabular}

$61.5 \%$ Mortality was seen among the 75-84yrs age group, 40\% Mortality was seen among the 8594yrs age group, $34.2 \%$ Mortality was seen among the 65-74yrs age group, 20\% Mortality was seen among the 45-54yrs age group and $13.8 \%$ Mortality was seen among the 55-64yrs age group. There was a statistical significant difference found between age group and outcome. $35.3 \%$ mortality among female and $27.3 \%$ mortality among male. There was no a statistical significant difference found between gender and outcome.

$43.6 \%$ mortality among the subjects who had hypertension and only $21.3 \%$ mortality among the subjects who did not had hypertension. There was a statistical significant difference found between Hypertension and outcome. 44.4\% mortality among the subjects who had Diabetes Mellitus and only $28.6 \%$ mortality among the subjects who did not had Diabetes Mellitus. There was no a statistical significant difference found between Diabetes Mellitus and outcome.

$27.3 \%$ mortality was found in smoker and $32.1 \%$ mortality was found in non-smoker. There was no a statistical significant difference found between Smoking and outcome.33.3\% mortality was found in alcoholic and $28.4 \%$ mortality was found in non-alcoholic. There was no a statistical significant difference found between alcohol and outcome.

Table 2: Comparison of mean age SBP, DBP, MAP with Outcome

\begin{tabular}{|l|c|c|c|c|c|}
\hline \multirow{2}{*}{} & \multicolumn{2}{|c|}{ Survived } & \multicolumn{2}{c|}{ Dead } & \multirow{2}{*}{ P Value } \\
\cline { 2 - 5 } & Mean & SD & Mean & SD & \\
\hline Age in years & 63.60 & 10.13 & 69.30 & 10.81 & 0.017 \\
\hline SBP (in mmhg) & 139.54 & 18.27 & 150.33 & 30.40 & 0.031 \\
\hline DBP (in mmhg) & 84.06 & 11.86 & 92.60 & 18.51 & 0.007 \\
\hline MAP (in mmhg) & 102.55 & 13.43 & 111.84 & 21.95 & 0.011 \\
\hline
\end{tabular}

Mean age was $63.60 \pm 10.13$ yrs among the survived subjects and $69.30 \pm 10.81 \mathrm{yrs}$ among dead subjects. There was a statistical significant difference found between mean age and outcome. 
Mean SBP was $139.54 \pm 18.27 \mathrm{mmhg}$ among the survived subjects and $150.33 \pm 30.40 \mathrm{mmhg}$ among dead subjects. There was a statistical significant difference found between mean SBP and outcome. Mean DBP was $84.06 \pm 11.86 \mathrm{mmhg}$ among the survived subjects and $92.60 \pm 18.51 \mathrm{mmhg}$ among dead subjects. There was a statistical significant difference found between mean DBP and outcome. Mean MAP was $102.55 \pm 13.43 \mathrm{mmhg}$ among the survived subjects and 111.84 $\pm 21.95 \mathrm{mmhg}$ among dead subjects. There was a statistical significant difference found between mean MAP and outcome.

Table 3: Association between admission blood pressure with mortality

\begin{tabular}{|c|c|c|c|c|c|}
\hline \multirow{4}{*}{ SBP(mmhg) } & & \multicolumn{2}{|c|}{ Survived } & \multicolumn{2}{c|}{ Dead } \\
\cline { 2 - 6 } & & $\mathrm{N}$ & $\%$ & $\mathrm{~N}$ & $\%$ \\
\cline { 2 - 6 } & $<120$ & 4 & $50.0 \%$ & 4 & $50.0 \%$ \\
\cline { 2 - 6 } & $121-140$ & 40 & $85.1 \%$ & 7 & $14.9 \%$ \\
\cline { 2 - 6 } & $141-160$ & 23 & $71.9 \%$ & 9 & $28.1 \%$ \\
\cline { 2 - 6 } & $161-180$ & 2 & $22.2 \%$ & 7 & $77.8 \%$ \\
\cline { 2 - 6 } DBP(mmhg) & $>180$ & 1 & $25.0 \%$ & 3 & $75.0 \%$ \\
\cline { 2 - 6 } & $60-69$ & 2 & $40.0 \%$ & 3 & $60.0 \%$ \\
\cline { 2 - 6 } & $70-79$ & 13 & $86.7 \%$ & 2 & $13.3 \%$ \\
\cline { 2 - 6 } & $80-89$ & 31 & $88.6 \%$ & 4 & $11.4 \%$ \\
\cline { 2 - 6 } & $90-99$ & 20 & $60.6 \%$ & 13 & $39.4 \%$ \\
\cline { 2 - 6 } & $100-109$ & 3 & $60.0 \%$ & 2 & $40.0 \%$ \\
\cline { 2 - 6 } & $>=110$ & 1 & $14.3 \%$ & 6 & $85.7 \%$ \\
\hline
\end{tabular}

$50 \%$ Mortality was seen in the subjects who had admission systolic Blood pressure <120mmhg. $77.8 \%$ Mortality was seen in the subjects who had admission systolic Blood pressure 161-180mmhg. $75 \%$ Mortality was seen in the subjects who had admission systolic Blood pressure >180mmhg. Both the extremity low and high admission systolic BP had very high mortality. 60\% Mortality was seen in the subjects who had admission Diastolic Blood pressure 60-69mmhg. $85.7 \%$ Mortality was seen in the subjects who had admission Diastolic Blood pressure $\geq 110 \mathrm{mmhg}$. Both the extremity low and high admission Diastolic BP had very high mortality.

\section{Discussion}

In our study the mean age of the study subjects was $65.31 \pm 10.61 \mathrm{yrs}$. Where as in study done Johan- Emil Bager et al ${ }^{16}$ the mean age was 78.4 \pm 8 yrs.In our study $39 \%$ of subjects had Hypertension and 9\% subjects had type 2 diabetes mellitus. Where as in study done Johan- Emil Bager et al $^{16} 57 \%$ had hypertension and $17 \%$ had DM.In our study mean systolic BP was 142 \pm 22.97 mmhg, mean diastolic BP was 86.62 \pm 14.62 , mean MAP was $105.34 \pm 16.88$. Where as in study done Johan- Emil Bager et $\mathrm{al}^{16}$ mean systolic BP was $166 \pm 29.7 \mathrm{mmhg}$, mean diastolic $\mathrm{BP}$ was $92 \pm 16.2 \mathrm{mmhg}$, mean MAP was $116 \pm$ $18.4 \mathrm{mmhg}$.

Our results clearly indicate that both high and low admission BP-values are associated with a poor outcome in stroke patients. Previous studies have addressed the association of high admission BP with stroke mortality in patients with very high admission

BP-values or in those with impaired consciousness ${ }^{[7,14]}$ whilst some others have found an association of high admission BP-values with poor functional outcome ${ }^{[10,11,17]}$.

The mechanisms underlying this relationship are poorly defined but it can presumably be explained by the hypothesis that hypertension promotes early stroke recurrence, symptomatic haemorrhagic transformation and formation of cerebral oedema ${ }^{[10,12,18,19]}$. According to the IST study, which included nearly 18000 ischaemic stroke patients, high BP-values were associated with early recurrent stroke and fatal brain oedema [10] 
Low admission BP-values were also associated with high mortality rates. Patients with heart failure and ischaemic myocardial disease are usually on antihypertensive medication and have, in comparison with other patients, a significantly lower cardiac output. It has been supported that low BP and low cardiac output result in cerebral hypoperfusion, which may cause larger ischaemic infarcts ${ }^{[20]}$. In the IST low admission SBP-values were associated with a severe clinical stroke (total anterior circulation syndrome) ${ }^{[10]}$.

Our study finding are similar to the some International studies in which a "U" curve relationship between BP and in-hospital mortality, where both highand low BP were associated with an increased early fatality ratio ${ }^{21 .}$

\section{Conclusion}

The described U-shaped curve appears to relate BP to clinical outcome, with the best outcome observed in normal or mildly elevated admission BP values, suggesting that both extremely high and extremely low admission BP-values are likely to affect outcome adversely.

\section{References}

1. Wallace JD, Levy LL. Blood pressure after stroke. JAMA 1981; 246: 2177-80.

2. Britton M, Carlsson A, de Faire U. Blood pressure course in patients with acute stroke and matched controls. Stroke 1986; 17: 861-4.

3. Powers WJ. Acute hypertension after acute stroke: the scientific basis for treatment decisions. Neurology 1993; 43:461-7.

4. Strandgaard S, Olsen J, Skinjøj E, Lassen NA. Autoregulation of brain circulation in severe arterial hypertension. BMJ 1973; 1: 507-10.

5. Myers M G, Norris J W, Hachniski VC, Sole MJ. Plasma norepinephrine in stroke. Stroke 1981; 12: 200-4.

6. Carlberg B, Asplund K, Hagg E. Factors influencing admission blood pressure levels in patients with acute stroke. Stroke,1991; 22: 527-30.

7. Britton M, Carlsson A. Very high blood pressure in acute stroke. J Intern Med 1990; 228: 611-5.

8. Dandapani BK, Suzuki S, Kelley R,et al. Relation between blood pressure and outcome in intracerebral haemorrhage. Stroke 1995; 26: 21-24.

9. Robinson TG, Dawson SL, Ahmed U, et al. Twenty-four-hour systolic blood pressure predicts long-term mortality following acute stroke. J Hypertens2001; 19: 2127-34.

10. Leonardi B J, Bath PM, Phillips SJ, et al. Blood pressure and clinical .... outcomes in the International Stoke Trial. Stroke 2002; 33: 1315-20.

11. Ahmed N, Wahlgren N. High initial blood pressure after acute stroke is associated with poor functional outcome. J Intern Med 2001; 249: 467-73.

12. Irie K, Yamaguchi T, Minematsu K, et al. The J-curve phenomenon in stroke recurrence. Stroke 1993; 24: 1844-9.

13. Tuhrim S, Dambrosia JM, Price TR et al. Prediction of intracerebral haemorrhage survival. Ann Neurol 1988; 24: 258-63.

14. Carlberg B, Asplund K, Hagg E. The prognostic value of admission blood pressure in patients with acute stroke. Stroke, 1993; 24: 1372-5.

15. Boreas AM, Lodder J, Kessels F, de Leeuw PW, Troost J.Prognostic value of blood pressure in acute stroke. J Hum Hypertens 2002; 16: 111-6.

16. Bager, Johan-Emil \& Hjalmarsson, Clara \& Manhem, Karin \& Andersson, Bjorn. (2018). Acute blood pressure levels and long- term outcome in ischemic stroke. Brain and Behavior. 8. 10.1002/brb3.992.

17. Robinson T, Waddington A, Ward-Close $\mathrm{S}$, Taub N, Potter J.The predictive role of 24-hour compared to casual bloodpressure 
levels on outcome following acute stroke.

Cerebrovasc Dis 1997; 7: 264-72.

18. Bath FJ, Bath PMW. What is the correct management of blood pressure in acute stroke? The blood pressure in Acute Stroke Collaboration. Cerebrovasc Dis 1997; 7: 205-13.

19. Hatashita S, Hoff JT, Ishii S. Focal brain oedema associated with acute arterial hypertension. J Neurosurg 1986; 64: 6439.

20. Lisk DR, Grotta JC, Lamki LM et al. Should hypertension be treated after acute stroke? A randomized controlled trial using single photon emission computed tomography. Arch Neurol 1993; 50: 85562.

21. Geeganage CM, Bath PM. Relationship between therapeutic changes in blood pressure and outcomes in acute stroke: a metaregression. Hypertension. 2009 Oct; 54

(4):775-81. https://doi.org/10.1161/HYPERTENSION AHA.109.133538. 